\title{
The characteristics of field-aligned currents associated with equatorial plasma bubbles as observed by the CHAMP satellite
}

\author{
J. Park ${ }^{1,2}$, H. Lühr ${ }^{1}$, C. Stolle ${ }^{1}$, M. Rother ${ }^{1}$, K. W. Min ${ }^{2}$, and I. Michaelis ${ }^{1}$ \\ ${ }^{1}$ Helmholtz-Center Potsdam (GFZ), German Research Center for Geosciences, Telegrafenberg, 14473 Potsdam, Germany \\ ${ }^{2}$ Department of Physics, Korea Advanced Institute of Science and Technology, 305-701 Daejeon, Korea
}

Received: 19 February 2009 - Revised: 5 June 2009 - Accepted: 30 June 2009 - Published: 7 July 2009

\begin{abstract}
Field-aligned currents (FACs) generate magnetic deflections perpendicular to the ambient Earth magnetic field. We investigate the characteristics of FACs associated with equatorial plasma bubbles (EPBs) as deduced from magnetic field measurements by the CHAMP satellite. Meridional magnetic deflections inside EPBs show a clear hemispheric anti-symmetry for events observed before 21:00 LT: inward in the Northern Hemisphere and outward in the Southern Hemisphere. When an eastward electric field is assumed the magnetic signature signifies a Poynting flux directed downward along the magnetic field lines. This means that FACs are driven by a high-altitude equatorial source. Such a scheme cannot be drawn as strictly from our observations after 22:00 LT, possibly because of a westward turning of the electric field inside EPBs and/or a decay of EPBs later at night. The perpendicular magnetic deflection is tilted by $40^{\circ}$ from the magnetic meridional plane in westward direction, which implies that the depleted volume of EPBs, as well as the FAC structure, is tilted westward by $40^{\circ}$ above the magnetic equator. The peak-to-peak amplitude of the FAC density is found to range typically between $0.1-0.5 \mu \mathrm{A} / \mathrm{m}^{2}$. The field-aligned sheet current density and the diamagnetic current strength show no correlation.
\end{abstract}

Keywords. Ionosphere (Electric fields and currents; Equatorial ionosphere; Ionospheric irregularities)

\section{Introduction}

The term "equatorial plasma bubble (EPB)" stands for a region of plasma density depletion in the post-sunset equatorial ionospheric F-layer. This phenomenon has been investigated with a variety of techniques since its first observation

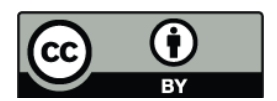

Correspondence to: J. Park (park@gfz-potsdam.de) by Booker and Wells (1938) using radio wave experiments: ground-based ionosonde (e.g. Argo and Kelley, 1986; Jayachandran et al., 1997; Saito and Maruyama, 2007), spacebased ionosonde (e.g. Muldrew, 1980a,b), incoherent scatter radar (e.g. Mendillo et al., 1992; Flaherty et al., 1996), coherent scatter radar (e.g. Hysell et al., 1990; Rodrigues et al., 2008), ground-based GPS receiver (e.g. Pi et al., 1997; Chen et al., 2006), satellite GPS receiver (e.g. Straus et al., 2003), in-situ satellite probe (e.g. Livingston et al., 1981; Kil and Heelis, 1998; Huang et al., 2001; Park et al., 2005; Su et al., 2008), in-situ rocket probe (e.g. Chandra et al., 1997; Sekar et al., 1997; Sinha et al., 1999), all-sky airglow camera (e.g. Mendillo and Tyler, 1983; Kim et al., 2002; Sahai et al., 2006; Yao and Makela, 2007), and space-based ultraviolet imager (e.g. Kelley et al., 2003; Immel et al., 2003). EPBs are aligned with the geomagnetic flux tube (e.g. Tsunoda, 1980), and elongated also vertically (e.g. Lee et al., 2005, and references therein). They usually persist for several hours after sunset (e.g. Somayajulu et al., 1975), and exert a baneful influence upon L-band GPS communication (e.g. Basu et al., 2002). The following ambient conditions are known to be favorable to EPB generation: (1) when the upward plasma drift around sunset is fast enough so that the ionosphere is lifted to high altitude (e.g. Fejer et al., 1999; Stolle et al., 2008), (2) during high solar activity periods (e.g. Sahai et al., 2000; Huang et al., 2002), (3) when fast downward neutral wind blows (e.g. Devasia et al., 2002), (4) when transequatorial neutral wind is negligible so that the plasma density asymmetry between Northern and Southern Hemispheres is small (e.g. Maruyama and Matuura, 1984; Mendillo et al., 1992), and (5) when the sun sets simultaneously at magnetically conjugate E-regions (e.g. Tsunoda, 1985) to unload the F-region dynamo. As these ambient conditions vary with the time of the year each season shows a specific longitudinal pattern of EPB distribution: a broad occurrence peak above the Atlantic ocean during equinoxes, African and Pacific peaks during June solstice, and a sharp South-American peak

Published by Copernicus Publications on behalf of the European Geosciences Union. 
during December solstice (e.g. Kil and Heelis, 1998; Huang et al., 2001; Park et al., 2005; Stolle et al., 2006). Electron temperatures inside EPBs are generally lower than that of the ambient (Oyama et al., 1988), but sometimes higher due to adiabatic compression along the flux tube ( $\mathrm{Su}$ et al., 2003; Park et al., 2008). In spectral respect EPBs are self-similar steepened structures when the ion-neutral collision frequency is high (Hysell et al., 1994), but similar to Kolmogorov turbulence in collisionless environments (Shume and Hysell, 2004).

There have also been a lot of theoretical and computational analyses to clarify the generation mechanism of EPBs (e.g. Ossakow and Chaturvedi, 1978; Sultan, 1996; Basu, 2002; Schunk and Demars, 2003; Bernhardt, 2007; Huba and Joyce, 2007). It is generally accepted that EPBs originate from the Generalized Rayleigh-Taylor instability (GRTI) (e.g. Sultan, 1996). This instability amplifies bottomside seed perturbations which may come from gravity waves (Hysell et al., 1990; Singh et al., 1997b), sporadicE (Es) layers (Tsunoda, 2007), or large-scale wave structures (Tsunoda, 2008). Contributing terms in the GRTI equation come from gravity, ambient E-field, neutral wind, and recombination loss (see Eq. 26 in Sultan, 1996). Among them F-region recombination loss was shown to have negligible effect on EPB growth rate (Huba et al., 1996). The growth rate of GRTI can be calculated by either local (Rappaport, 1996), flux-tube-integrated (Sultan, 1996), or ballooning-mode ambient parameters (Basu, 2002), whose merits and demerits are elaborated on in Basu (2002). EPBs are described by linear GRTI at its initial stages, but non-linear dynamics should be introduced at later stages at the topside ionosphere (Kuo et al., 1998). Sekar and Kelley (1998) showed that, as EPBs grow from the bottom to topside ionosphere, vertical shear in the zonal plasma drift leads to EPB westward tilt. Simulation results of Schunk and Demars (2003) showed that the existence of EPBs deforms the profile of thermospheric neutral density in a complex way. Recently, Huba et al. (2008) succeeded in 3-D modeling of EPB evolution.

In classical EPB theories magnetic perturbation due to the presence of EPBs has been neglected. It was only recently that researchers expressed interest in magnetic signature of EPBs. Aggson et al. (1992) observed radially outward magnetic perturbations around the westward wall of EPBs. They suggested that the magnetic perturbation was a signature of shear Alfvén wave and associated field-aligned currents (FACs), which in turn originated from EPB kinetic energy. In a circuit model in their Fig. 7c FACs propagate oppositely from the equatorial generator (i.e. EPBs) and make outward (inward) magnetic deflection in the Southern (Northern) Hemisphere. Under the assumption of eastward E-field the Poynting flux given by the magnetic deflections is always poleward. The idea was theoretically elaborated on by Bhattacharyya and Burke (2000) and Basu (2005). Bhattacharyya and Burke (2000) set up a circuit model with transmission lines, where oppositely flowing FACs launched by
EPBs form a closed circuit by polarization current and Eregion Pedersen current. As is well known, current flowing through the E-region load suppresses EPB growth, but the effect is alleviated by the polarization current and following signal loss during the field-aligned propagation of FACs. According to Basu (2005) the magnetic signature generally diffuses quickly and its influence on EPB growth is quite small. Stolle et al. (2006) showed observationally that EPBs are accompanied by both (a) an enhancement of the magnetic field strength and (b) magnetic perturbation perpendicular to the ambient field. (a) is associated with diamagnetic current flowing perpendicular to the ambient B-field. Gyromotion of plasma particles generates diamagnetic current, which decreases the magnetic field strength inside dense plasmas (Aggson et al., 1992; Lühr et al., 2003). The diamagnetic current flows perpendicular to the plane defined by the plasma pressure gradient and the ambient magnetic field, and leads to an enhancement of the B-field inside EPBs, which balances the plasma pressure decrease (Stolle et al., 2006). Stolle et al. (2006) tested whether the effect of diamagnetic current can be detected within the EPB scale length, and successfully showed that EPB density structures are reflected in the enhancement of B-field strength. (b) is an evidence of FACs flowing along EPBs (e.g., Aggson et al., 1992; Bhattacharyya and Burke, 2000). Stolle et al. (2006) discussed the direction of observed outward/inward B-field to test the circuit model of Aggson et al. (1992) and Bhattacharyya and Burke (2000). However, a significant amount of observations did not agree with the circuit model, i.e. the magnetic deflection was not always outward (inward) in the Southern (Northern) Hemisphere. Recently, Pottelette et al. (2007) observed electromagnetic fluctuation at EPB edges, and estimated the edge thickness to be $\sim 1 \mathrm{~km}$. They also estimated FAC density for one example, which amounted to $0.2 \mu \mathrm{A} / \mathrm{m}^{2}$.

The source of FACs is still controversial. There is a consensus that they result from the divergence of zonal crossfield currents associated with EPBs (see Aggson et al., 1992; Pottelette et al., 2007). The ionospheric current, $\boldsymbol{j}$, consists of a number of contributions: gravity-driven current, pressure gradient current, and current related with the ambient E-field (Kelley, 1989; Maus and Lühr, 2006; Stolle et al., 2006):

$\boldsymbol{j}=\boldsymbol{\sigma}(\boldsymbol{E}+\boldsymbol{u} \times \boldsymbol{B})+\frac{1}{B^{2}}\left[n_{e} m_{i} \boldsymbol{g} \times \boldsymbol{B}-k_{B} \nabla\left\{\left(T_{e}+T_{i}\right) n_{e}\right\} \times \boldsymbol{B}\right]$

where $\boldsymbol{\sigma}$ is the conductivity tensor, $\boldsymbol{E}$ the electric field, $\boldsymbol{u}$ the wind velocity, $\boldsymbol{B}$ the ambient magnetic field, $n_{e}$ the electron number density, $m_{i}$ the ion mass, $g$ the gravitational acceleration, $k_{B}$ the Boltzmann constant, $T_{e}$ and $T_{i}$ are the electron and ion temperatures. Aggson et al. (1992) argued that the diamagnetic current (last term) is divergence-free and thus does not contribute to FACs. Bhattacharyya and Burke (2000) stated that the F-region current source for FACs is the gravity-driven current and neglected the pressure gradient term from the very beginning. However, they also argued that 
the current flowing through the E-region load, which is fed by FAC, can suppress EPB growth. It implies that FAC and diamagnetic current (characterizing plasma pressure gradient, i.e. EPB strength) might be indirectly related. Pottelette et al. (2007) attributed FACs to the interception of gravity-driven perpendicular currents by insulating EPBs. Yet, there has been no decisive observational evidence to determine which term of the cross-field current dominates FAC generation.

The Stolle et al. (2006) paper provided the first extensive statistical study devoted to the magnetic field variations inside EPBs, but there still remains room for further investigations. First, they showed that the FAC circuit model of Aggson et al. (1992) and Bhattacharyya and Burke (2000) is not always valid. However, they did not tell exactly when or where the model is valid/invalid. Second, only the meridional component of magnetic deflection was taken into consideration, and no special statistics of the zonal component was shown. As FACs flow along the EPB edges (Pottelette et al., 2007) the orientation of resultant magnetic deflections (determined by both zonal and meridional components) should characterize the EPB geometry. Third, they only concentrated on the direction of FAC, while the amplitude of FAC density was not calculated. In case we know the FAC amplitude, its correlation with other cross-field currents such as gravity-driven current can be investigated to clarify what is the dominant source of FACs. In this paper we will make use of CHAMP magnetic field observations and address the above three issues in detail. In Sect. 2 we describe the instruments and event selection process. The statistical results are shown in Sect. 3, and their implications are discussed in Sect. 4. A summary is given in Sect. 5 .

\section{Observations}

The Challenging Mini-satellite Payload (CHAMP) was launched in July 2000. Its orbit altitude was about $450 \mathrm{~km}$ right after the launch, and decayed down to $340 \mathrm{~km}$ in 2008 . The orbit inclination angle with respect to the equatorial plane is $87.3^{\circ}$. One main objective of the satellite mission is the accurate measurement of the geomagnetic field. For that purpose a Flux Gate Magnetometer (FGM) and a scalar Overhauser Magnetometer (OVM) are operated onboard. The FGM takes measurements with a resolution of $0.1 \mathrm{nT}$ at a rate of $50 \mathrm{~Hz}$. The preprocessed FGM data are scaled and decimated to a rate of $1 \mathrm{~Hz}$. OVM provides measurements with a time resolution of $1 \mathrm{~s}$. These absolute data are used to cross-calibrate FGM readings. In order to probe the ambient ionospheric plasma CHAMP also carries a Digital Ion Drift Meter (DIDM) and a Planar Langmuir Probe (PLP). DIDM was designed to measure the 3$\mathrm{D}$ ion drift velocity vector, the plasma density, and temperatures, but it was severely degraded during launch and remained uncalibrated. However, occasionally we still can get qualitative plasma density readings from DIDM at 1 s reso- lution. PLP measures absolute plasma density every $15 \mathrm{~s}$. All those instruments are still in operation as of May 2009. The preprocessed level 2 data are open to public access at http://isdc.gfz-potsdam.de/index.php.

The magnetic field sensed by the CHAMP/FGM consists of a variety of contributions such as from the Earth's core, crust, magnetospheric current, and ionospheric plasma. To isolate ionospheric effects in the geomagnetic field vector, which are the main focus of the paper, we need a precise geomagnetic field model for removing the rest. The Potsdam Magnetic Model of the Earth, Version 4 (POMME4) is an empirical geomagnetic field model based on CHAMP observations (http://www.gfz-potsdam.de/magmodels/POMME4) being the next generation of POMME3 (Maus et al., 2006). With the input of time, location, interplanetary magnetic field and ring current index, the model returns corresponding geomagnetic field vectors including contributions from the core, crustal, and magnetospheric current components. The output is called "mean" field for a given time and location. In this work we subtract the mean field derived from POMME4 from the CHAMP/FGM data. The resulting "residual" field is then transformed into the mean-field-aligned (MFA) coordinate system, where the z-component, "parallel," is along the mean field, the y-component, "zonal," is perpendicular to the magnetic meridian and is pointing to the east, and the $\mathrm{x}$-component, "meridional," completes the triad and points outward. A similar approach was used in Stolle et al. (2006), Park et al. (2008), and Park et al. (2009). Remaining largescale variations of order $10 \mathrm{nT}$, which are not properly allowed for by POMME4, are further eliminated with a 91 point $(\sim 700 \mathrm{~km})$ median filter in Sects. 3 and 4.

We followed the scheme of Stolle et al. (2006) to detect EPBs within $\pm 40^{\circ}$ invariant latitude and 18:00-02:00 local time (LT) from 2001 to 2002. First, the parallel component is high-pass filtered $\left(T_{c}=30 \mathrm{~s}\right)$ and rectified. If the result exceeds $0.2 \mathrm{nT}$ during quiet time $\left(K_{p}<4.7\right)$, it is considered as an EPB. But, an EPB event should be located between two $20 \mathrm{~s}$ segments of calm background (filtered and rectified parallel component $<0.15 \mathrm{nT}$ ), so that nearby smallscale deflections are merged together to form an EPB event. In this study EPBs shorter than 20 data points $(\sim 150 \mathrm{~km})$ are neglected as we want to evaluate the correlation coefficients between the parallel, zonal, and meridional B-field components. Furthermore, an EPB is discarded if one of the star cameras is out of operation in-between, or when more than 10 data points are missing within the EPB. Stand-alone data jumps and unreasonably large deflections are rejected, too. Inside each EPB zonal and meridional residual fields are high-pass filtered and rectified $\left(T_{C}=180 \mathrm{~s}\right)$. When one of these deflections has the maximum less than $0.4 \mathrm{nT}$ the EPB is disused for this study because the perpendicular deflection within EPBs is the main topic of this paper.

Figure 1 shows a typical nighttime CHAMP data interval. Respective panels show variations in the (a) meridional, (b) zonal, and (c) parallel magnetic field components 


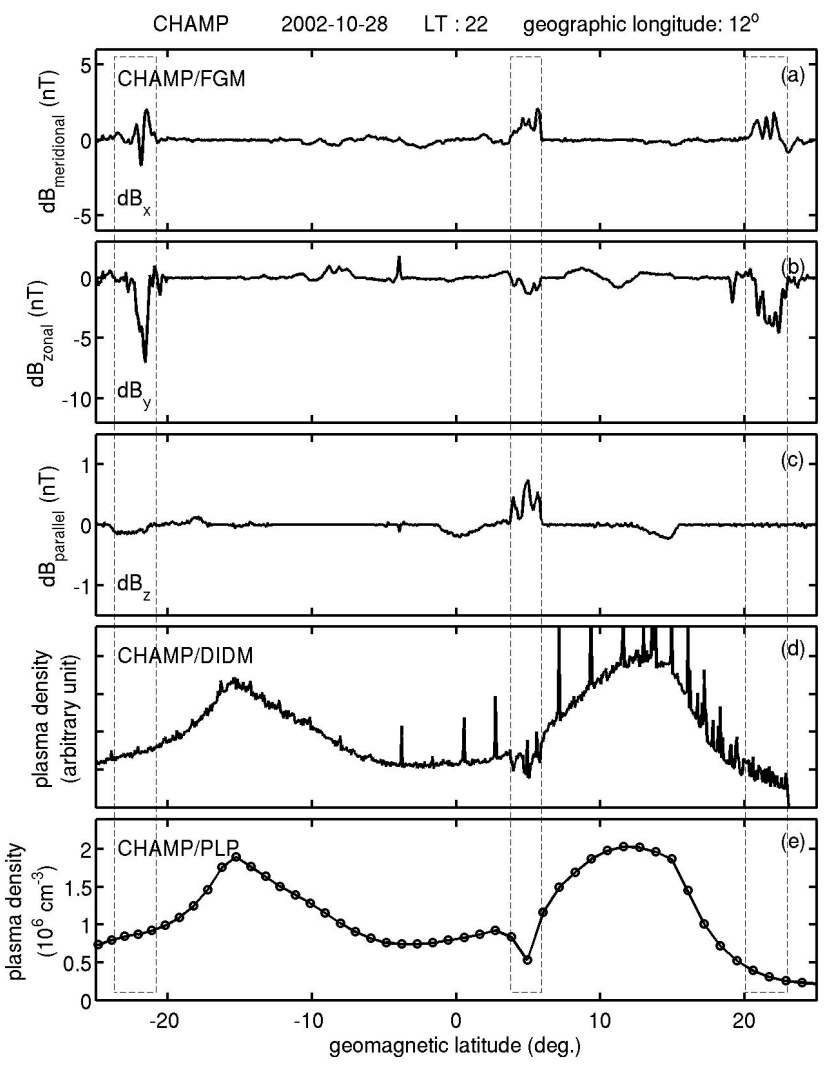

Fig. 1. An example of EPB encountered by CHAMP: (a) meridional B-field, (b) zonal B-field, (c) parallel B-field in MFA coordinate system, (d) relative plasma density measured by DIDM, and (e) absolute plasma density measured by PLP. Solitary positive spikes in panel (d) are outliers.

obtained by FGM, (d) relative plasma density measured by DIDM, and (e) the absolute plasma density derived from PLP. Solitary positive spikes in panel (d) are outliers. Among the three dotted rectangular boxes the central one shows an EPB event. We can see a clear plasma density depletion between the two Appleton anomaly peaks in panels (d) and (e). The parallel component (panel c) is enhanced inside the EPB. The B-field enhancement is generated by diamagnetic currents. Its small-scale structure is quite consistent with that of the plasma density shown in panel (d). Inside the EPB the meridional component in panel (a) increases (i.e. outward deflection), and the zonal component in panel (b) decreases (i.e. westward deflection). Similar characteristics of the magnetic deflection associated with EPBs have been found in Stolle et al. (2006). In contrast, the left and right boxes have clear magnetic signatures in meridional and zonal components but nothing conspicuous in the parallel component or the plasma density. These events are located outside the Appleton anomaly. Therefore they might not be EPBs but mid-latitude magnetic fluctuations (MMFs) connected with medium-scale traveling ionospheric disturbances (MSTIDs) as reported by Park et al. (2009). In this work we will focus only on EPBs which are identified with fluctuations in the parallel component of the magnetic field.

\section{Statistical analysis of FACs}

\subsection{Meridional B-field}

As a first step we investigate the meridional magnetic deflections inside EPBs. To begin with, we qualitatively check whether the meridional B-field points outward or inward inside an EPB, rather than dealing with its magnitude. The correlation coefficient between the parallel and meridional components is calculated for every EPB detected by the abovementioned procedure. We extended the correlation interval by $10 \mathrm{~s}$ on both sides of an EPB. Only events returning correlation coefficients larger than $|0.6|$ are taken into account. About 940 EPBs pass this criterion from $\sim 1900$ detected events in total. Because the parallel component always increases within an EPB, the meridional component is judged to be inward (outward) when the correlation coefficient is negative (positive). Later, the statistical distribution of inward/outward EPBs in each local time bin is considered separately.

First, Fig. 2 shows the global distribution of all EPBs with good correlation $(|R|>0.6)$. The seasonal/longitudinal $(\mathrm{S} / \mathrm{L})$ distribution is given as percentage encounters in (a) equinoxes (March, April, September, and October), (b) June solstice (May-August), and (c) December solstice (November-February). Panel (d) shows the EPB distribution with respect to local time and invariant latitude. Panels (ac) are smoothed by a 3-by-3 median filter. The distribution pattern is consistent with previous works (e.g. Kil and Heelis, 1998; Huang et al., 2001; Park et al., 2005; Stolle et al., 2006; $\mathrm{Su}$ et al., 2008). However, the percentage occurrence rate is smaller due to the additional constraints on the meridional magnetic component. From Fig. 2 we can see that the following results are not biased seasonally/longitudinally by our more stringent selection criteria.

Figure 3 presents the direction of the magnetic field meridional deflection within EPBs for various local time intervals: 18:00-20:00 LT, 20:00-21:00 LT, 21:00-22:00 LT, 22:00-23:00 LT, 23:00-24:00 LT, and 00:00-02:00 LT. From the figures we can see that the direction of meridional deflections shows a hemispherically anti-symmetric distribution before 21:00 LT: it is inward in the Northern Hemisphere and outward in the south. The anti-symmetry begins to be compromised during the hour 21:00-22:00 LT, and it practically disappears afterwards.

\subsection{Transverse B-field variations}

In this subsection we investigate the zonal component together with the meridional one. Similarly, EPBs are detected by the parallel deflections as described in Sect. 2. Among them are considered only EPBs whose meridional and zonal 
(a) equinoxes $(3,4,9,10)$

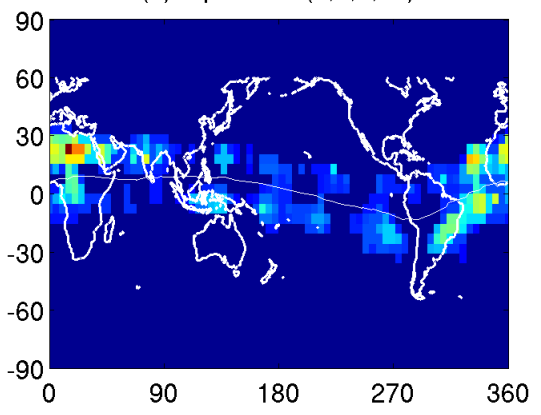

(c) December solstice $(1,2,11,12)$

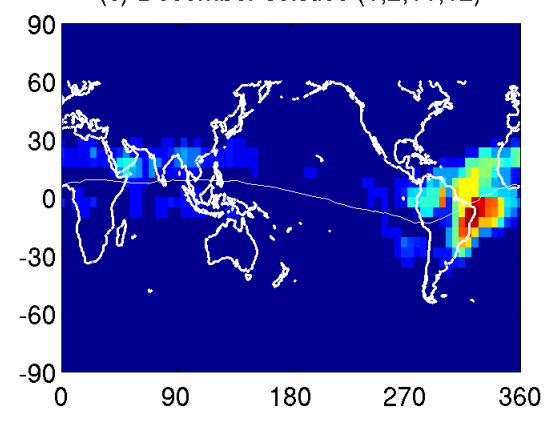

(b) June solstice $(5,6,7,8)$

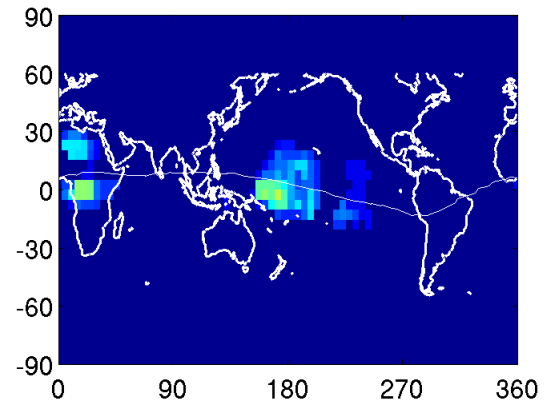

(d) all seasons

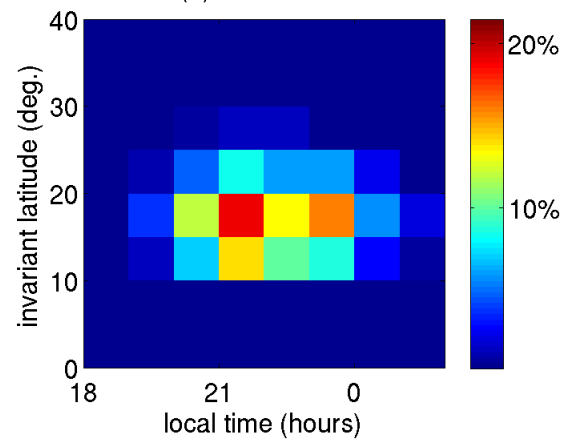

Fig. 2. Distribution of EPBs exhibiting a high degree of correlation between meridional and parallel magnetic field deflections. Seasonal/longitudinal (S/L) distribution is shown: (a) equinoxes (March, April, September, and October), (b) June solstice (May-August), and (c) December solstice (November-February). Panel (d) illustrates the EPB distribution with respect to local time and invariant latitude. Note that the latitudinal range of our analysis is limited to values below $\left|40^{\circ}\right|$ invariant latitude.

components have a correlation coefficient higher than $|0.6|$. About 650 EPBs passed this test from the $\sim 1900$ events in total. We consider the perpendicular magnetic deflection in the "zonal" versus the "meridional" direction. Inside an EPB we plot all the data points from these two components onto the plane (as shown later in Fig. 5a). The linear regression line is obtained by the total least square method, which assumes an equal distribution of the uncertainties in both components. The slope of the line is translated into an angle (termed "mean polarization angle"): $0^{\circ}-90^{\circ}$ represent positive slopes, $90^{\circ}-180^{\circ}$ negative slopes. Figure 4 shows the distribution of the mean polarization angles for local times between 18:00 LT and 02:00 LT. The thin red line represents a Gaussian fit to the histogram. We can see a clear peak around $130^{\circ}$ irrespective of the hemisphere. At the equator it corresponds to a westward tilt of $40^{\circ}$ from the vertical plane. When mapped onto the E-layer at $110 \mathrm{~km}$ altitude, the footprint is tilted westward by about $65^{\circ}$ with respect to the magnetic meridian.

\subsection{FAC density calculation}

For cases where the perpendicular magnetic deflections are linearly polarized inside an EPB, like the events selected in Sect. 3.2, we can calculate the FAC density, $j_{z}$, from
Ampère's law:

$j_{z}=\frac{1}{\mu_{0}}\left(\frac{\partial B_{y}}{\partial x}-\frac{\partial B_{x}}{\partial y}\right)$

where $\mu_{0}$ is the permeability of free space. Since we have magnetic field observations only from a single satellite spatial gradients have to be derived from recorded temporal changes occurring over a given distance. For our events Eq. (2) can be modified to:

$j_{z}=-\frac{1}{\mu_{0}} \frac{B_{\perp}(t+d t)-B_{\perp}(t)}{s(t+d t)-s(t)}$

where $B_{\perp}$ is the magnetic deflection along the mean polarization direction, $s$ the component of the CHAMP path perpendicular to the polarization plane. The EPB shown in Fig. 1 is an example of such qualified events and is reproduced in Fig. 5. The top panel contains a scatterplot of zonal versus meridional magnetic deflections. The resulting mean polarization angle is $128^{\circ}$. The middle panel shows the magnetic deflection along the mean polarization direction (regression line). The bottom panel presents the FAC density calculated according to Eq. (3). Finally the FAC curve is median lowpass filtered $\left(T_{c}=2 \mathrm{~s}\right)$. The peak-to-peak amplitude of the FAC density is about $0.5 \mu \mathrm{A} / \mathrm{m}^{2}$. Figure 6 is the statistical 
18 to20LT
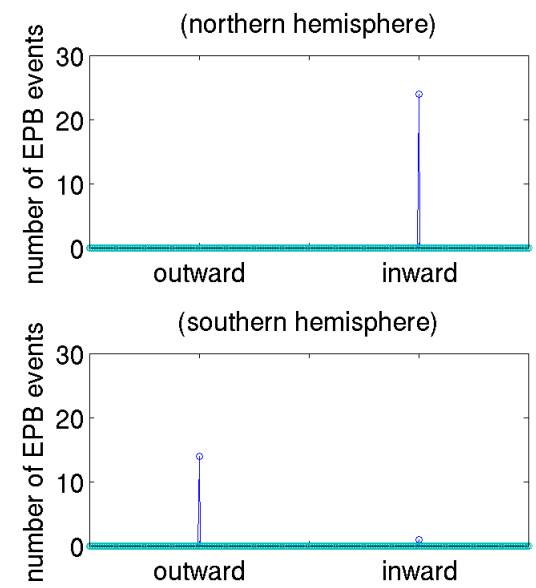

21 to22LT
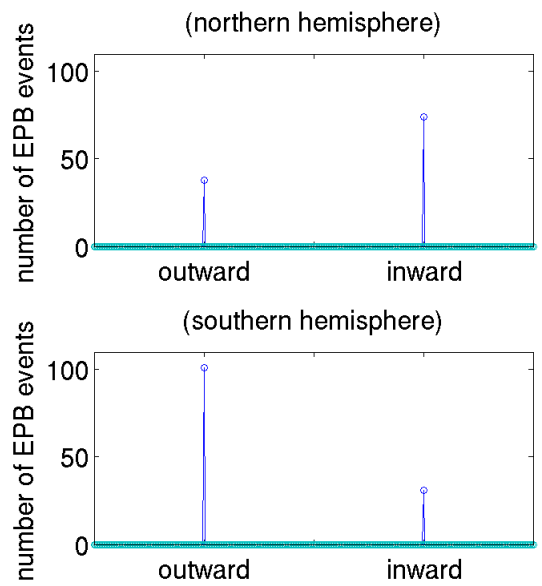

23to24LT
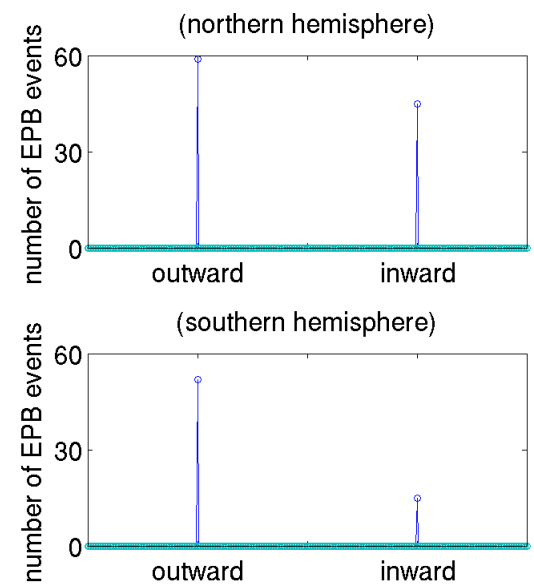

20to21LT
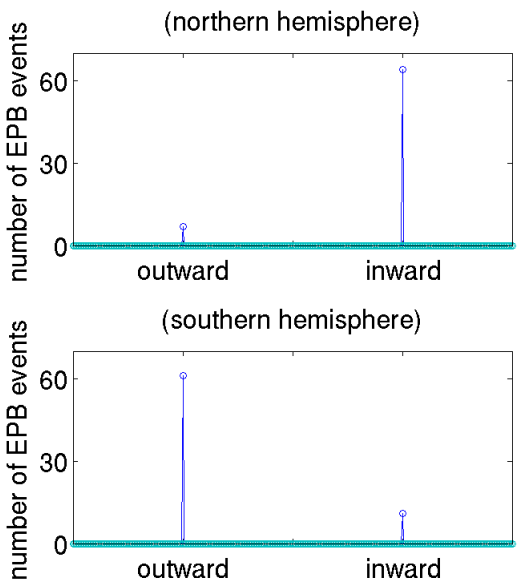

22to23LT
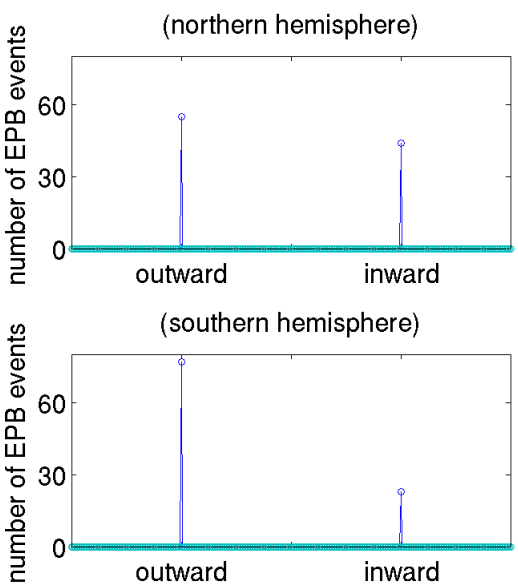

24to26LT
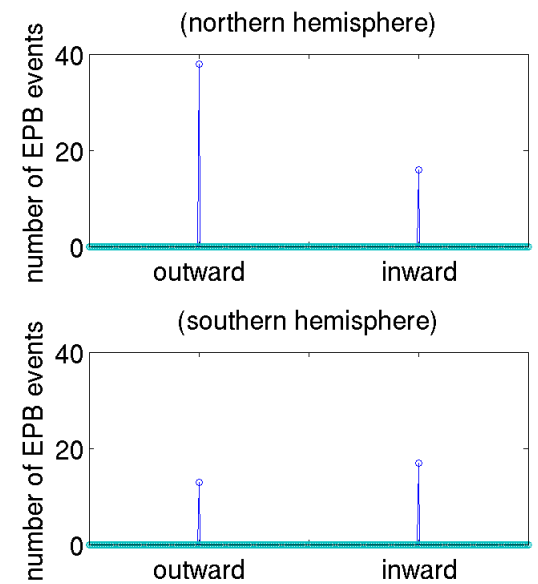

Fig. 3. Local time variation of the magnetic field meridional deflection within EPBs separately shown for the Northern and Southern Hemispheres. 

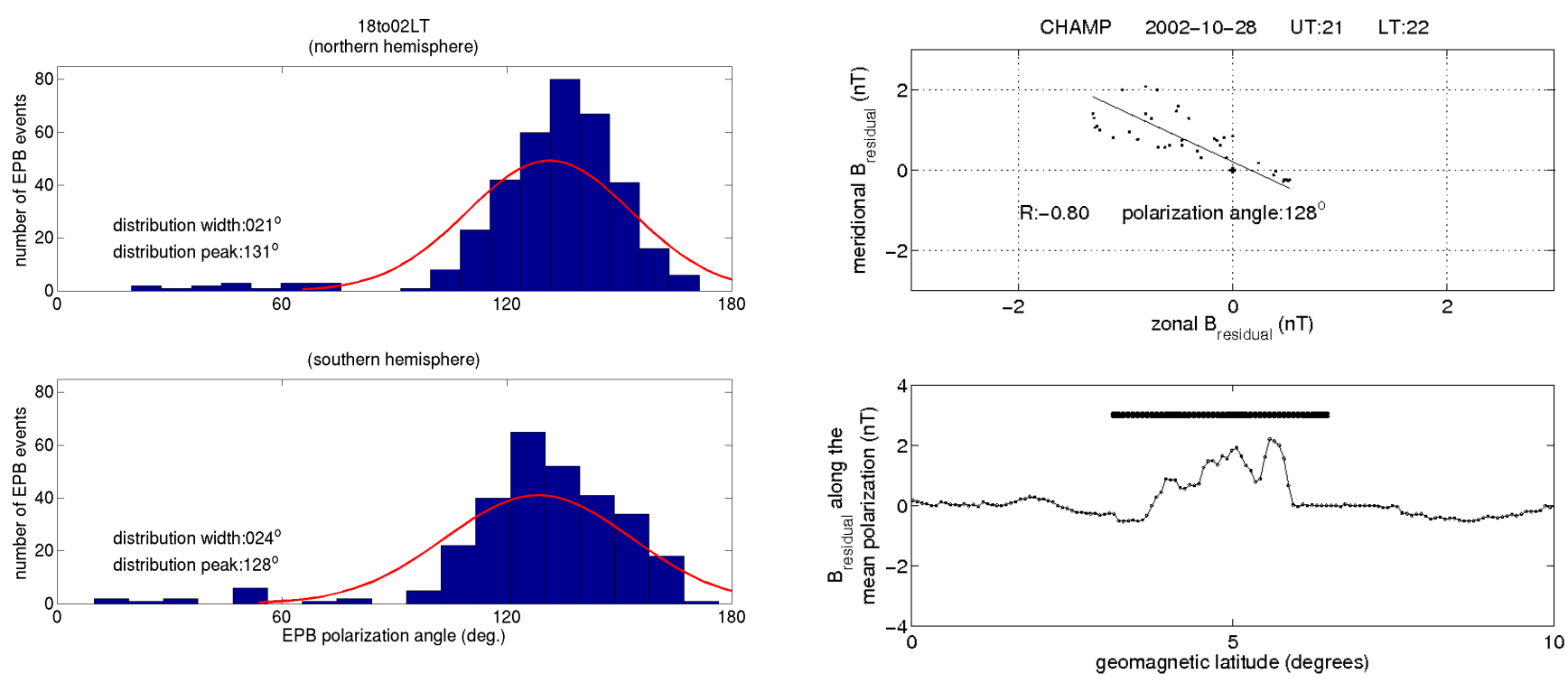

Fig. 4. Distribution of polarization angles derived from EPB events between 18:00 and 02:00 LT. An angle of $0^{\circ}$ corresponds to a direction magnetically eastward, $90^{\circ}$ deflection within the magnetic meridian, and $180^{\circ}$ towards magnetic west. The thin red line represents a Gaussian fit to the histogram.

distribution of peak-to-peak FAC amplitudes. When compiling the statistics we excluded intervals where the component of the CHAMP velocity perpendicular to the polarization plane is less than $0.7 \mathrm{~km} / \mathrm{s}$ because it might produce unphysically large current densities according to Eq. (3). As can be seen in Fig. 6, a majority of EPBs have peak-to-peak FAC amplitudes below $0.5 \mu \mathrm{A} / \mathrm{m}^{2}$.

\subsection{Relationship between FAC and diamagnetic current}

Here we want to investigate whether there is a relationship between FAC intensity and diamagnetic current strength. The diamagnetic current, $J_{d}$, can be estimated from the average change of the B-field strength, $\Delta|B|$, inside the EPB:

$J_{d}=\frac{\Delta|B|}{\mu_{0}}$

where $J_{d}$ is the average diamagnetic sheet current density and $\Delta|B|$ is the averaged change of the B-field strength across an EPB.

In order to obtain an appropriate quantity for comparison from the FACs we integrate the absolute strength of the current density across the EPB event:

$J_{\|}=\frac{1}{2} \int\left|j_{\|}\right| d s$

where $j_{\|}$is the current density as obtained from Eq. (3) and $d s$ is the integration path perpendicular to the FAC sheet, in our case the component of the CHAMP path perpendicular to the polarization plane. The factor $\frac{1}{2}$ reflects the assumption of a balance between upward and downward currents.

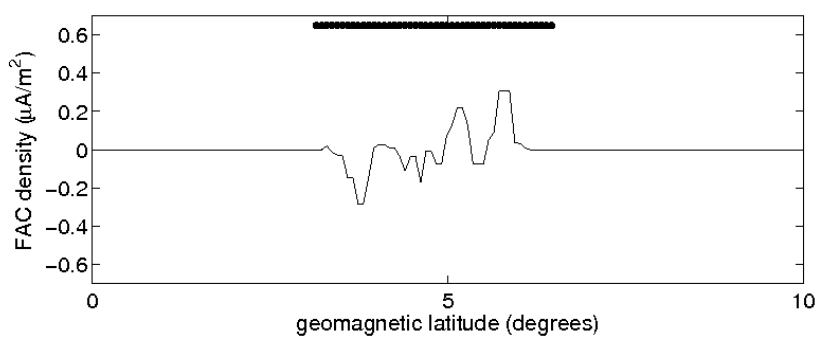

Fig. 5. Example of FAC density calculation for the EPB event presented in Fig. 1. (top panel) scatter plot of the zonal versus meridional magnetic deflections, (middle panel) the magnetic deflections along the mean polarization direction, (bottom panel) FAC density calculated according to Eq. (3) and then low-pass filtered ( $\left.T_{c}=2 \mathrm{~s}\right)$. Horizontal black bars represent the EPB locations (with 10-point margins at both sides) determined by the automated procedure described in Sect. 2.

Figure 7 shows the relation between the diamagnetic current sheet density according to Eq. (4) and the FAC sheet density calculated by Eq. (5). There cannot be seen any conspicuous correlation, and the absolute value of the coefficient is less than 0.1 .

\section{Discussion}

In Sect. 3 we presented a statistical survey of the EPB magnetic signatures perpendicular to the mean field, which is associated with FACs flowing along EPB walls. Based on the result we will investigate the electrodynamic nature of $\mathrm{EPB}$ evolution. As described in Sect. 2, the data set is restricted to solar maximum years from 2001 to 2002 and to the local time sector from 18:00 LT to 02:00 LT because EPB activity is highest within this time window. Also, we used only EPBs occurring when $K_{p}<4.7$ to focus on its quiet-time 


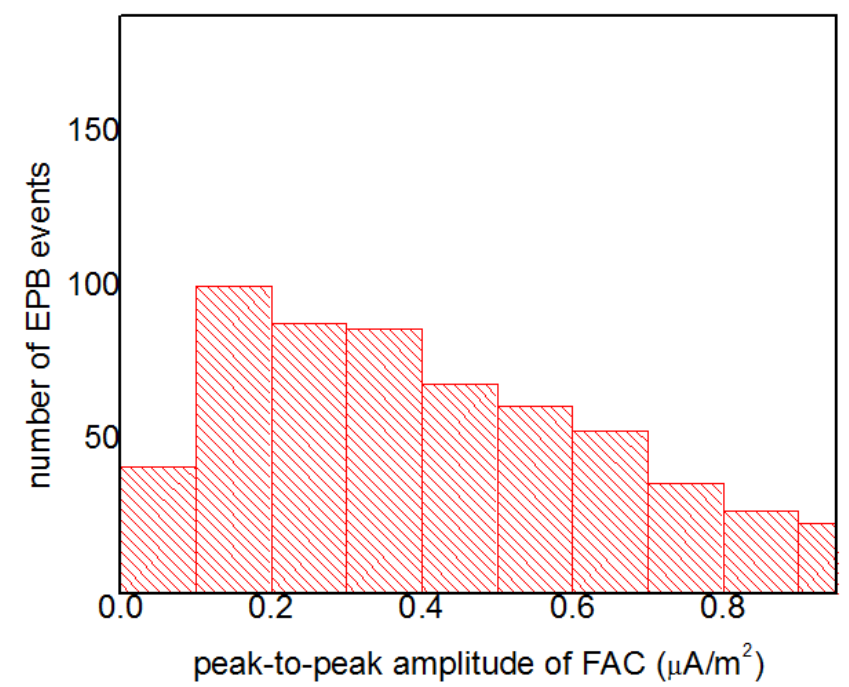

Fig. 6. Statistical distribution of peak-to-peak FAC density amplitude.

behavior. An EPB event is only taken into account when both star cameras are in operation. This is because attitude noise is enhanced by a factor of 3 to 5 when readings from only one head are available, which can introduce spurious signals in the magnetic field vector data. Therefore, the data given in this paper is representative of solar-maximum early night EPBs, and is quite independent of attitude noise or stormtime ionospheric variations.

\subsection{Meridional B-field and Poynting flux}

The meridional deflection in Fig. 3 shows a clear hemispheric anti-symmetry before 21:00 LT: inward in the Northern Hemisphere and outward in the Southern Hemisphere. Unfortunately, CHAMP/DIDM does not provide the ion velocity (ionospheric E-field). We therefore assume the direction of the zonal E-field in the depleted flux tube based on previous works. Laakso et al. (1997) argued that the zonal E-field component inside an EPB is the sum of the ambient E-field and the contributions from the gravitational term and neutral wind. Among them the gravitational term produces always an eastward field, but the result of the other two terms depends on the prevailing ambient conditions. For example, the ambient E-field turns westward between 19:0021:00 LT. The actual reversal time depends on solar flux, season, and longitude (Fejer et al., 2008). According to Laakso et al. (1997), the zonal E-field within an EPB is mainly eastward before 21:00 LT, but may turn westward afterwards, i.e. (1) when the ambient E-field turns westward, (2) when the influence of the gravitational term is low due to a higher ionneutral collision frequency, e.g. at low altitudes $(<400 \mathrm{~km})$, (3) and for zero or upward neutral wind. Combined with these findings, our Fig. 3 suggests that the Poynting flux before 21:00 LT is predominantly directed downward along the

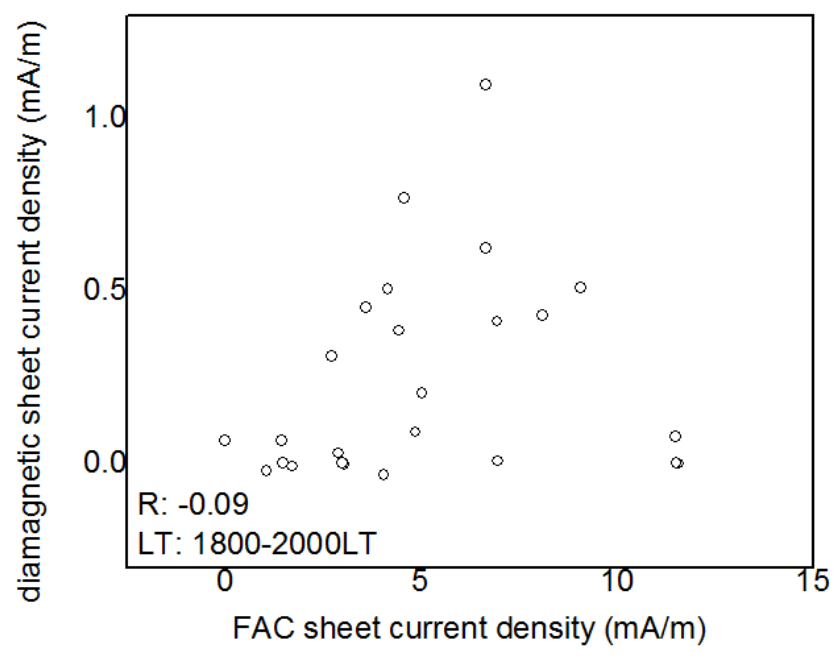

Fig. 7. Correlation diagram between sheet current density of FACs and of diamagnetic currents.

flux tubes in both hemispheres, which is consistent with the circuit model of Aggson et al. (1992) and Bhattacharyya and Burke (2000).

The trend for hemispherically anti-symmetric magnetic deflection even persists during the hour 21:00 to 22:00 LT although a number of counter-examples have appeared. The anti-symmetry practically disappears afterwards, which might have two reasons. First, the zonal E-field inside EPBs may have turned westward after 22:00 LT (Laakso et al., 1997). In such cases meridional magnetic deflection should be flipped by $180^{\circ}$ to produce the same direction of Poynting flux. Second, the Poynting vector itself might not be poleward any more after 22:00 LT. Equation (32) of Bhattacharyya and Burke (2000) suggests that the Poynting vector related with EPBs is poleward during the growth phase, and the magnitude is a function of EPB growth rate. However, we cannot say that the same argument is applicable to the period when an EPB ceases to grow and starts to decay. Singh et al. (1997a) showed that EPB occurrences are reduced after 21:30 LT and suggested that EPBs will decay after their initial growth phase. Therefore, the direction of the meridional magnetic deflection may not have a simple trend after 21:30 LT, but shows a complex behavior, as can be seen in Fig. 3.

\subsection{Zonal B-field and westward tilt of EPBs}

In Fig. 4 the mean polarization angles are $\sim 130^{\circ}$ irrespective of hemispheres. First, when mapped to the equatorial plane, it corresponds to a westward EPB tilt $\sim 40^{\circ}$ from the vertical. This value is consistent with previous observations on EPB tilt angles (Mendillo and Tyler, 1983; Mukherjee, 2003; Makela and Kelley, 2003). Such tilts are known to be caused by vertical shear of the zonal plasma drift. Due to a stronger westward plasma drift at higher altitudes EPBs 
grow into the upward/westward direction (Sekar and Kelley, 1998; Shiokawa et al., 2004, and references therein). The shear itself might come from a height-dependent efficiency of the ion-neutral coupling (Zalesak et al., 1982), or from a reduced eastward neutral wind at latitudes away from the dip equator (Anderson and Mendillo, 1983; Liu et al., 2009) (see also Sect. 3 of Shiokawa et al., 2004). Second, when we map the mean polarization angle in Fig. 4 onto the E-layer at $110 \mathrm{~km}$ height, the zonal component remains unchanged but the meridional component is reduced by the sine of the dip angle. Therefore, the mapped polarization angle becomes larger than the angle with respect to the meridional plane. The result gives an EPB westward tilt of $\sim 65^{\circ}$ with respect to magnetic north. This can be compared to Fig. 1 of Kelley et al. (2003), where EPB flux tubes are shown in global $135.6 \mathrm{~nm}$ airglow images (projected onto $150 \mathrm{~km}$ altitude) obtained by TIMED/GUVI. In their figure the EPB flux tubes are tilted westward by $\sim 45^{\circ}$ in general, which is in qualitative agreement with our result. In conclusion, the linear polarization of EPB magnetic signatures around $130^{\circ}$ may be a natural consequence of the westward tilt of the EPB geometry. Our study gives the first statistical evidence of EPB westward tilt from global, long-term data bases.

The envisaged geometry of EPBs is schematically illustrated in Fig. 8. It summarizes our findings on EPB electrodynamics for events occurring before 21:00 LT. In panel (a) the EPB flux tubes are projected along the B-field and mapped onto a conducting layer at the bottomside ionosphere. In both hemispheres we find oppositely directed FAC sheets: upward in the east and downward in the west. The FAC sheets are closed in the conducting layer by Pedersen current $j_{P}$. From previous observations (e.g. Laakso et al., 1997), it is known that the electric field in the EPBs is eastward during the early hours after sunset. As the scalar product of E-field times $j_{P}$ is positive, the closure current acts as a load in the circuit, which is consistent with the circuit model of Bhattacharyya and Burke (2000). This implies that we have a generator above the equator producing downward Poynting flux into both hemispheres (Aggson et al., 1992; Bhattacharyya and Burke, 2000; Stolle et al., 2006). Magnetic perturbations associated with FACs $\left(B_{\perp}\right)$ have both meridional and zonal components. The meridional components are directed southward in both hemispheres. While the zonal component points to the east in the northern hemisphere and to the west in the southern, the footprints of EPBs at the bottomside ionosphere are tilted westward by $\sim 65^{\circ}$ from the magnetic meridian. Our suggestion for explaining this tilt is illustrated in Fig. 8b, which borrows some idea from Fig. 8 of Kil and Paxton (2009).

The basic idea behind this current configuration is that currents are generated in the topside region of EPBs, i.e. the mechanical energy of EPBs is converted into electromagnetic energy at the topside leading edge, as suggested by Aggson et al. (1992). These currents are routed along B-field lines. During the downward propagation they are closed across (a)

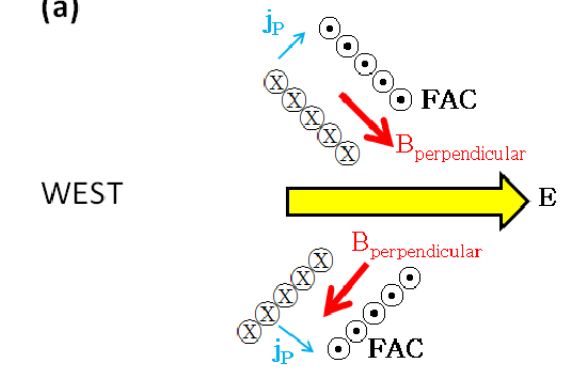

\section{EAST}

(b)

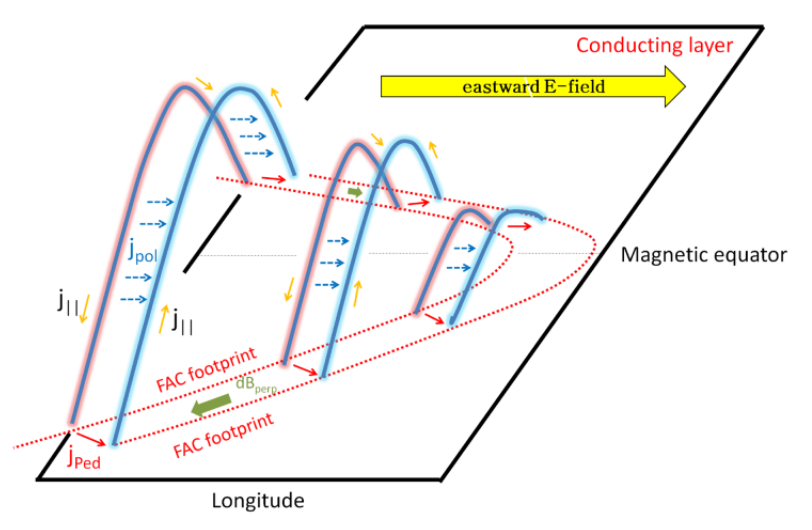

Fig. 8. Two schematic illustrations of EPB geometry: (a) a top view of the EPB projected along B-field onto a conducting layer at the bottomside ionosphere. (b) a 3-D view of the westward-tilted EPB and its footprint in the conducting layer. Adjacent pairs of field lines form elementary current circuits.

the B-field (1) by polarization currents in the F-regions and (2) by Pedersen currents in lower conducting layers of both hemispheres (Bhattacharyya and Burke, 2000). Since EPBs are dynamical features, the depleted plasma regions are tilted towards west. As described above, higher flux tubes are displaced to the west due to vertical shear of the plasma drift. The line of foot prints at a fixed altitude form a contour similar to an inverted "C" (Kelley et al., 2003). During the early hours after sunset (18:00-21:00 LT) field lines of the western wall carry downward/poleward currents and those of the eastern wall upward/equatorward currents. Currents between the two inverted "C" contours in bottomside conducting layers, as well as polarization currents in the F-region, close the loop between the two walls. During later local time hours (after 22:00 LT) the situation might be quite different.

\subsection{FAC and diamagnetic current}

In Fig. 6 we can see that most of the considered EPBs have amplitudes between $0.1-0.5 \mu \mathrm{A} / \mathrm{m}^{2}$. The occurrence number in the lowest-amplitude bin $\left(0.0-0.1 \mu \mathrm{A} / \mathrm{m}^{2}\right)$ is 
under-represented because many of the small events were disregarded by our threshold criterion (e.g. $>0.2 \mathrm{nT}$ for the parallel deflection), but this is of no concern for the derived conclusions. Pottelette et al. (2007) estimated the FAC density for one EPB example and reported the value $0.2 \mu \mathrm{A} / \mathrm{m}^{2}$, which is well in line with our results. It is also interesting to note that the obtained amplitudes are comparable to FAC densities associated with MSTIDs (Saito et al., 1995; Park et al., 2009).

As stated in Sect. 1, FACs originate from the divergence of cross-field currents. According to Basu et al. (2002) and our Eq. (1) the relevant cross-field current consists of gravity-driven current and E-field driven Pedersen/Hall current. Unfortunately, we cannot quantify gravity-driven or E-field driven currents from CHAMP observations. Concerning their particular roles in FAC generation further investigations are needed. From Eq. (1) we can see that the diamagnetic current also contributes to the cross-field current. Though the diamagnetic current itself is divergencefree and does not contribute directly to FAC generation (Aggson et al., 1992), it would be interesting to check whether FACs and diamagnetic currents are (indirectly) connected with each other. In Fig. 7 we investigated the relationship between sheet current strengths of diamagnetic current and FAC. Here, the local time is restricted to 18:00 LT-20:00 LT, i.e. the time of active EPB evolution. Later local time sectors are excluded because dead EPBs (no downward/poleward Poynting flux) or downdrafting EPBs (westward E-field inside) might make the electrodynamics more complex (see Fig. 3). We can see no obvious correlation between the two currents. The result suggests that FAC intensities are independent of the diamagnetic current strength. Concerning the possible role of the other two cross-field currents further investigations are needed. Our favored mechanism for the current generation at the top of EPBs is the vertical plasma drift. The horizontal magnetic field lines at equatorial latitudes cause a charge separation in east/west direction. For neutralizing these charges FACs are set up routing the currents into both hemispheres. The circuit is expected to be closed in the F-region by polarization currents and in lower conducting layers by Pedersen currents. The speed and direction of the plasma drift is determined by the superposition of several contributions. Important factors are the disruption of the gravity-driven currents by the EPBs, the large-scale zonal electric field and the influence of the vertical neutral wind. It would be interesting to correlate the plasma drift with the FAC intensity. Unfortunately, CHAMP does not provide drift measurements. These issues can be addressed much more appropriately with ESA's upcoming multi-spacecraft Swarm mission, as it is designed to measure the electric field and plasma density with high time resolution.

\subsection{Significance of the result}

In Sects. 3.1 and 3.2 the number of qualified EPBs is only about half and one-third of the total number of events, respectively. One might ask whether the result is representative of generic EPB signatures. Rejected events in our analysis, e.g. EPBs whose magnetic deflections are poorly correlated with each other, might consist of smaller unresolved sub-EPBs at different flux tubes. Each sub-EPB can exhibit different orientation and amplitude of B-field deflection, as each has a different density gradient and geometry. Another possibility is that CHAMP has passed the EPB close to the nose of the inverted "C." Here the directions of magnetic field deflection are changing over small scales. Therefore, it is no wonder that only a portion of the detected EPBs show good linear correlation between the B-field components. However, once they are linearly correlated within the whole EPB, the electrodynamic features deduced from the magnetic deflections agree well with the physical description presented in previous works: poleward/downward Poynting flux between 18:00-21:00 LT, westward EPB tilt, and FAC densities around $0.3 \mu \mathrm{A} / \mathrm{m}^{2}$.

\section{Summary}

In our paper we analyzed the electromagnetic behavior of EPBs as deduced from magnetic field measurements by the CHAMP/FGM instrument. The following features are found in our study.

1. Meridional magnetic deflections inside EPBs show a clear hemispheric anti-symmetry for events observed before 21:00 LT: inward in the Northern Hemisphere and outward in the Southern Hemisphere. As the zonal E-field inside EPBs is predominantly eastward before 21:00 LT (Laakso et al., 1997), the magnetic signature signifies a Poynting flux directed downward along the magnetic field lines from a high-altitude equatorial source, which is consistent with Aggson et al. (1992), Bhattacharyya and Burke (2000) and with the cartoon (Fig. 12) in Stolle et al. (2006). This hemispherical antisymmetry begins to be compromised between 21:0022:00 LT, and practically disappears afterwards. The reason might be a westward turning of the EPB E-field (Laakso et al., 1997) and/or a decay of EPBs (Bhattacharyya and Burke, 2000) later at night.

2. The perpendicular magnetic deflection is tilted by $40^{\circ}$ from the magnetic meridional plane in westward direction. As FACs flow along the EPB edges (Pottelette et al., 2007), the observed B-field deflection implies that the depleted volume of EPBs is tilted westward by $40^{\circ}$ above the magnetic equator. This result is consistent with Mendillo and Tyler (1983) and Mukherjee (2003). When mapped to the E-layer at $110 \mathrm{~km}$ altitude, the line 
connecting the flux tubes is tilted westward by $65^{\circ}$ from magnetic north (cf. Fig. 8b). This is also in general agreement with airglow images, as presented by Kelley et al. (2003).

3. The peak-to-peak amplitude of the FAC density is found to range typically between $0.1-0.5 \mu \mathrm{A} / \mathrm{m}^{2}$. Fieldaligned sheet current density and diamagnetic current strength show no correlation. The diamagnetic currents are by about an order of magnitude weaker.

Acknowledgements. The CHAMP mission is supported by the German Aerospace Center (DLR) in operation and by the Federal Ministry of Education (BMBF), as part of the Geotechnology Programme, in data processing. The work of J. Park was partially supported by the Korea Research Foundation Grant funded by the Korean Government (MOEHRD) (KRF-2007-357-C00041).

Topical Editor M. Pinnock thanks two anonymous referees for their help in evaluating this paper.

\section{References}

Aggson, T. L., Burke, W. J., Maynard, N. C., Hanson, W. B., Anderson, P. C., Slavin, J. A., Hoegy, W. R., and Saba, J. L.: Equatorial bubbles updrifting at supersonic speed, J. Geophys. Res., 97, 8581-8590, 1992.

Anderson, D. N. and Mendillo, M.: Ionospheric conditions affecting the evolution of equatorial plasma depletions, Geophys. Res. Lett., 10, 541-544, 1983.

Argo, P. E. and Kelley, M. C.: Digital ionosonde observations during equatorial spread F, J. Geophys. Res., 91, 5539-5555, 1986.

Basu, B.: On the linear theory of equatorial plasma instability: Comparison of different descriptions, J. Geophys. Res., 107, 1199, doi:10.1029/2001JA000317, 2002.

Basu, B.: Characteristics of electromagnetic Rayleigh-Taylor modes in nighttime equatorial plasma, J. Geophys. Res., 110, A02303, doi:10.1029/2004JA010659, 2005.

Basu, S., Groves, K. M., Basu, S., and Sultan, P. J.: Specification and forecasting of scintillations in communication/navigation links: current status and future plans, J. Atmos. Solar-Terr. Phys., 64, 1745-1754, 2002.

Bernhardt, P. A.: Quasi-analytic models for density bubbles and plasma clouds in the equatorial ionosphere: Closed form solutions for electric fields and potentials, J. Geophys. Res., 112, A01302, doi:10.1029/2006JA011606, 2007.

Bhattacharyya, A. and Burke, W. J.: A transmission line analogy for the development of equatorial ionospheric bubbles, J. Geophys. Res., 105, 24941-24950, 2000.

Booker, H. G. and Wells, H. W.: Scattering of radio waves by the F region of the ionosphere, J. Geophys. Res., 43, 249-256, 1938.

Chandra, H., Vyas, G. D., Sinha, H. S. S., Prakash, S., and Misra, R. N.: Equatorial spread-F campaign over SHAR, J. Atmos. Solar-Terr. Phys., 59, 191-205, 1997.

Chen, W. S., Lee, C. C., Liu, J. Y., Chu, F. D., and Reinisch, B. W.: Digisonde spread $\mathrm{F}$ and GPS phase fluctuations in the equatorial ionosphere during solar maximum, J. Geophys. Res., 111, A12305, doi:10.1029/2006JA011688, 2006.

Devasia, C. V., Jyoti, N., Subbarao, K. S. V., Viswanathan, K. S., Tiwari, D., and Sridharan, R.: On the plausible linkage of thermo- spheric meridional winds with the equatorial spread F, J. Atmos. Solar-Terr. Phys., 64, 1-12, 2002.

Fejer, B. G., Scherliess, L., and de Paula, E. R.: Effect of the vertical plasma drift velocity on the generation and evolution of equatorial spread F, J. Geophys. Res., 104, 19859-19869, 1999.

Fejer, B. G., Jensen, J. W., and Su, S.-Y.: Quiet-time equatorial $F$ region vertical plasma drift model derived from ROCSAT1 observations, J. Geophys. Res., 113, A05304, doi:10.1029/ 2007JA012801, 2008.

Flaherty, J., Kelley, M., Seyler, C., and Fitzgerald, T.: Simultaneous VHF and transequatorial HF observations in the presence of bottomside equatorial spread F, J. Geophys. Res., 64, 26811-26818, 1996.

Huang, C. Y., Burke, W. J., Machuzak, J. S., Gentile, L. C., and Sultan, P.: DMSP observations of equatorial plasma bubbles in the topside ionosphere near solar maximum, J. Geophys. Res., 106, 8131-8142, 2001.

Huang, C. Y., Burke, W. J., Machuzak, J. S., Gentile, L. C., and Sultan, P.: Equatorial plasma bubbles observed by DMSP satellites during a full solar cycle: Toward a global climatology, J. Geophys. Res., 107, 1434, doi:10.1029/2002JA009452, 2002.

Huba, J., Bernhardt, P., Ossakow, S., and Zalesak, S.: The RayleighTaylor instability is not damped by recombination in the $\mathrm{F}$ region, J. Geophys. Res., 101, 24553-24556, 1996.

Huba, J. D. and Joyce, G.: Equatorial spread F modeling: Multiple bifurcated structures, secondary instabilities, large density 'biteouts,' and supersonic flows, Geophys. Res. Lett., 34, L07105, doi:10.1029/2006GL028519, 2007.

Huba, J. D., Joyce, G., and Krall, J.: Three-dimensional equatorial spread F modeling, Geophys. Res. Lett., 35, L10102, doi: 10.1029/2008GL033509, 2008.

Hysell, D. L., Kelley, M., Swartz, W., and Woodman, R. F.: Seeding and Layering of Equatorial Spread F by Gravity Waves, J. Geophys. Res., 95, 17253-17260, 1990.

Hysell, D. L., Kelley, M., Swartz, W., Pfaff, R., and Swenson, C.: Steepened Structures in Equatorial Spread F, 1. New Observations, J. Geophys. Res., 99, 8827-8840, 1994.

Immel, T. J., Mende, S. B., Frey, H. U., Peticolas, L. M., and Sagawa, E.: Determination of low latitude plasma drift speeds from FUV images, Geophys. Res. Lett., 30, 1945, doi:10.1029/ 2003GL017573, 2003.

Jayachandran, P. T., Sri Ram, P., Somayajulu, V. V., and Rama Rao, P. V. S.: Effect of equatorial ionization anomaly on the occurrence of spread-F, Ann. Geophys., 15, 255-262, 1997, http://www.ann-geophys.net/15/255/1997/.

Kelley, M. C.: The Earth's Ionosphere: Plasma Physics and Electrodynamic, Academic Press, Inc. San Diego, 1989.

Kelley, M. C., Makela, J. J., Paxton, L. J., Kamalabadi, F., Comberiate, J. M., and Kil, H.: The first coordinated ground- and spacebased optical observations of equatorial plasma bubbles, Geophys. Res. Lett., 30, 1766, doi:10.1029/2003GL017301, 2003.

Kil, H. and Heelis, R. A.: Global distribution of density irregularities in the equatorial ionosphere, J. Geophys. Res., 103, 407-417, 1998.

Kil, H. and Paxton, L. J.: The morphology of the large equatorial plasma depletions observed during the 29-30 October 2003 storm, J. Atmos. Solar-Terr. Phys., submitted, 2009.

Kim, Y. H., Hong, S. S., and Weinberg, J. L.: Equatorial spread F found in 5577A and 6300A airglow observations from Hawaii, J. 
Geophys. Res., 107, 1264, doi:10.1029/2001JA009232, 2002.

Kuo, F., Chou, S., and Shan, S.: Comparison of topside and bottomside irregularities in equatorial $\mathrm{F}$ region ionosphere, J. Geophys. Res., 103, 2193-2199, 1998.

Laakso, H., Maynard, N. C., Pfaff, R. F., Aggson, T. L., Coley, W. R., Janhunen, P., and Herrero, F. A.: Electric field diagnostics of the dynamics of equatorial density depletions, J. Atmos. SolarTerr. Phys., 59, 1,625-1,631, 1997.

Lee, C.-C., Su, S.-Y., and Reinisch, B. W.: Concurrent study of bottomside spread $\mathrm{F}$ and plasma bubble events in the equatorial ionosphere during solar maximum using digisonde and ROCSAT-1, Ann. Geophys., 23, 3473-3480, 2005, http://www.ann-geophys.net/23/3473/2005/.

Liu, H., Watanabe, S., and Kondo, T.: Fast thermospheric wind jet at the Earth's dip equator, Geophys. Res. Lett., 36, L08103, doi: 10.1029/2009GL037377, 2009.

Livingston, R., Rino, C., McClure, J., and Hanson, W.: Spectral Characteristics of Medium-Scale Equatorial F Region Irregularities, J. Geophys. Res., 86, 2421-2428, 1981.

Lühr, H., Rother, M., Maus, S., Mai, W., and Cooke, D.: The diamagnetic effect of the equatorial Appleton anomaly: Its characteristics and impact on geomagnetic field modeling, Geophys. Res. Lett., 30, 1906, doi:10.1029/2003GL017407, 2003.

Makela, J. J. and Kelley, M. C.: Field-aligned 777.4-nm composite airglow images of equatorial plasma depletions, Geophys. Res. Lett., 30, 1442, doi:10.1029/2003GL017106, 2003.

Maruyama, T. and Matuura, N.: Longitudinal Variability of Annual Changes in Activity of Equatorial Spread F and Plasma Bubbles, J. Geophys. Res., 89, 10,903-10,912, 1984.

Maus, S. and Lühr, H.: A gravity-driven electric current in the Earth's ionosphere identified in CHAMP satellite magnetic measurements, Geophys. Res. Lett., 33, L02812, doi:10.1029/ 2005GL024436, 2006.

Maus, S., Rother, M., Stolle, C., Mai, W., Choi, S., Lühr, H., Cooke, D., and Roth, C.: Third generation of the Potsdam Magnetic Model of the earth (POMME), Geochem. Geophys. Geosyst., 7, Q07008, doi:10.1029/2006GC001269, 2006.

Mendillo, M. and Tyler, A.: Geometry of Depleted Plasma Regions in the Equatorial Ionosphere, J. Geophys. Res., 88, 5778-5782, 1983.

Mendillo, M., Baumgardner, J., Pi, X., Sultan, P., and Tsunoda, R.: Onset Conditions for Equatorial Spread F, J. Geophys. Res., 98, 13741-13750, 1992.

Mukherjee, G. K.: Studies of the equatorial F-region depletions and dynamics using multiple wavelength nightglow imaging, J. Atmos. Solar-Terr. Phys., 65, 379-390, 2003.

Muldrew, D.: The Formation of Ducts and Spread F and the Initiation of Bubbles by Field-Aligned Currents, J. Geophys. Res., 85, 613-625, 1980a.

Muldrew, D.: Characteristics of Ionospheric Bubbles Determined From Aspect Sensitive Scatter Spread F Observed With Alouette 1, J. Geophys. Res., 85, 2115-2123, 1980b.

Ossakow, S. L. and Chaturvedi, P.: Morphological Studies of Rising Equatorial Spread F Bubbles, J. Geophys. Res., 83, 2085-2090, 1978.

Oyama, K.-I., Schlegel, K., and Watanabe, S.: Temperature structure of plasma bubbles in the low latitude ionosphere around 600 km altitude, Planet. Space Sci., 36, 553-567, 1988.

Park, J., Min, K. W., Kim, V. P., Kil, H., Lee, J.-J., Kim, H.-
J., Lee, E., and Lee, D. Y.: Global distribution of equatorial plasma bubbles in the premidnight sector during solar maximum as observed by KOMPSAT-1 and Defense Meteorological Satellite Program F15, J. Geophys. Res., 110, A07308, doi: 10.1029/2004JA010817, 2005.

Park, J., Min, K. W., Kim, V. P., Kil, H., Su, S.-Y., Chao, C. K., and Lee, J.-J.: Equatorial plasma bubbles with enhanced ion and electron temperatures, J. Geophys. Res., 113, A09318, doi:10. 1029/2008JA013067, 2008.

Park, J., Lühr, H., C, S., Rother, M., Min, K. W., Chung, J. K., Kim, Y., Michaelis, I., and Noja, M.: Magnetic signatures of medium-scale traveling ionospheric disturbances (MSTIDs) as observed by CHAMP, J. Geophys. Res., 114, A09608, doi:10. 1029/2008JA013792, 2009.

Pi, X., Mannucci, A., Lindqwister, U., and Ho, C.: Monitoring of Global Ionospheric Irregularities Using the Worldwide GPS Network, Geophys. Res. Lett., 24, 2283-2286, 1997.

Pottelette, R., Malingre, M., Berthelier, J. J., Seran, E., and Parrot, M.: Filamentary Alfvénic structures excited at the edges of equatorial plasma bubbles, Ann. Geophys., 25, 2159-2165, 2007, http://www.ann-geophys.net/25/2159/2007/.

Rappaport, H.: Field line integration and localized modes in the equatorial spread F, J. Geophys. Res., 101, 24545-24552, 1996.

Rodrigues, F. S., Hysell, D. L., and de Paula, E. R.: Coherent backscatter radar imaging in Brazil: large-scale waves in the bottomside F-region at the onset of equatorial spread $F$, Ann. Geophys., 26, 3355-3364, 2008, http://www.ann-geophys.net/26/3355/2008/.

Sahai, Y., Fagundes, P. R., and Bittencourt, J. A.: Transequatorial Fregion ionospheric plasma bubbles: solar cycle effects, J. Atmos. Solar-Terr. Phys., 62, 1377-1383, 2000.

Sahai, Y., Abalde, J. R., Fagundes, P. R., Pillat, V. G., and Bittencourt, J. A.: Transequatorial F-region ionospheric plasma bubbles: solar cycle effects, Geophys. Res. Lett., 33, L11104, doi: 10.1029/2005GL025262, 2006.

Saito, A., Iyemori, T., Sugiura, M., Maynard, N. C., Aggson, T. L., Brace, L. H., Takeda, M., and Yamamoto, M.: Conjugate Occurrence of the Electric Field Fluctuations in the Nighttime Midlatitude Ionosphere, J. Geophys. Res., 100, 21439-21451, 1995.

Saito, S. and Maruyama, T.: Large-scale longitudinal variation in ionospheric height and equatorial spread F occurrences observed by ionosondes, Geophys. Res. Lett., 34, L16109, doi:10.1029/ 2007GL030618, 2007.

Schunk, R. W. and Demars, H. G.: Effect of equatorial plasma bubbles on the thermosphere, J. Geophys. Res., 108, 1245, doi: 10.1029/2002JA009690, 2003.

Sekar, R. and Kelley, M.: On the combined effects of vertical shear and zonal electric field patterns on nonlinear equatorial spread $\mathrm{F}$ evolution, J. Geophys. Res., 103, 20735-20747, 1998.

Sekar, R., Sridharan, R., and Raghavarao, R.: Equatorial plasma bubble evolution and its role in the generation of irregularities in the lower F region, J. Geophys. Res., 102, 20063-20067, 1997.

Shiokawa, K., Otsuka, Y., Ogawa, T., and Wilkinson, P.: Time evolution of high-altitude plasma bubbles imaged at geomagnetic conjugate points, Ann. Geophys., 22, 3137-3143, 2004, http://www.ann-geophys.net/22/3137/2004/.

Shume, E. B. and Hysell, D. L.: Spectral analysis of plasma drift measurements from the AE-E satellite: evidence of an inertial subrange in equatorial spread F, J. Atmos. Solar-Terr. Phys., 66, 
57-65, 2004.

Singh, S., Bamgboye, D. K., McClure, J. P., and Johnson, F. S.: Morphology of equatorial plasma bubbles, J. Geophys. Res., 102, 20019-20029, 1997a.

Singh, S., Johnson, F. S., and Power, R. A.: Gravity wave seeding of equatorial plasma bubbles, J. Geophys. Res., 102, 7399-7410, $1997 b$.

Sinha, H., Raizada, S., and Misra, R.: First Simultaneous in situ Measurement of Electron Density and Electric Field Fluctuations During Spread F in the Indian Zone, Geophys. Res. Lett., 26, 1669-1672, 1999.

Somayajulu, V. V., Sen Gupta, K., and Krishna Murthy, B. V.: Duration of equatorial spread F, Nature, 257, 112-113, 1975.

Stolle, C., Lühr, H., Rother, M., and Balasis, G.: Magnetic signatures of equatorial spread $\mathrm{F}$, as observed by the CHAMP satellite, J. Geophys. Res., 111, A02304, doi:1029/2005JA011184, 2006.

Stolle, C., Lühr, H., and Fejer, B. G.: Relation between the occurrence rate of ESF and the equatorial vertical plasma drift velocity at sunset derived from global observations, Ann. Geophys., 26, 3979-3988, 2008,

http://www.ann-geophys.net/26/3979/2008/.

Straus, P. R., Anderson, P. C., and Danaher, J. E.: GPS occultation sensor observations of ionospheric scintillation, Geophys. Res. Lett., 30, 1436, doi:10.1029/2002GL016503, 2003.

Su, S.-Y., Chao, C. K., Yeh, H. C., and Heelis, R. A.: Observations of shock impact, disturbance dynamo effect, and a midlatitude large-density depletion at $600 \mathrm{~km}$ altitude on the 17 April 2002 storm day, J. Geophys. Res., 108, 1310, doi: 10.1029/2002JA009752, 2003.
Su, S.-Y., Chao, C. K., and Liu, C. H.: On monthly/seasonal/longitidinal variations of equatorial irregularitiey occurrences and their relationship with the post-sunset vertical drift velocity, J. Geophys. Res., 113, A05307, doi: 10.1029/2007JA012809, 2008.

Sultan, P. J.: Linear theory and modeling of the Rayleigh-Taylor instability leading to the occurrence of equatorial spread $F$, J. Geophys. Res., 101, 26875-26891, 1996.

Tsunoda, R. T.: Magnetic-field-aligned characteristics of plasma bubbles in the nighttime equatorial ionosphere, J. Atmos. Terr. Phys., 42, 743-752, 1980.

Tsunoda, R. T.: Control of the seasonal and longitudinal occurrence of equatorial scintillations by the longitudinal gradient in integrated $E$ region Pedersen Conductivity, J. Geophys. Res., 90, 447-456, 1985.

Tsunoda, R. T.: Seeding of equatorial plasma bubbles with electric fields from an Es-layer instability, J. Geophys. Res., 112, A06304, doi:10.1029/2006JA012103, 2007.

Tsunoda, R. T.: Satellite traces: An ionogram signature for largescale wave structure and a precursor for equatorial spread F, Geophys. Res. Lett., 35, L20110, doi:10.1029/2008GL035706, 2008.

Yao, D. and Makela, J. J.: Analysis of equatorial plasma bubble zonal drift velocities in the Pacific sector by imaging techniques, Ann. Geophys., 25, 701-709, 2007, http://www.ann-geophys.net/25/701/2007/.

Zalesak, S. T., Ossakow, S. L., and Chaturvedi, P. K.: Nonlinear equatorial spread F: The effect of neutral winds and background Pedersen conductivity, J. Geophys. Res., 87, 151-166, 1982. 